\title{
A method for predicting the influence of matric suction changes on CPT tip resistance
}

\author{
Gerald A. Miller ${ }^{1, *}$, and Rodney W. Collins ${ }^{2}$ \\ ${ }^{1}$ University of Oklahoma, School of Civil Engineering and Environmental Science, 73019, USA \\ ${ }^{2}$ Midwest Engineering and Testing Corporation, 73128, USA
}

\begin{abstract}
The Cone Penetration Test (CPT) is a valuable tool for continuous soil profiling and estimating soil properties. A CPT sounding will often pass through the active zone of an unsaturated soil profile, near the ground surface where moisture conditions and matric suction can vary considerably with depth and time. For many projects, the active zone is also significant to the support of shallow foundations and overlying embankments. However, the strength and stiffness of the unsaturated soils in this zone can be significantly affected by variations in the moisture content and matric suction. Likewise, the cone penetration tip resistance and sleeve friction will be influenced by the variations in moisture conditions and suction. Therefore, it is important to consider the soil moisture conditions when CPTs are conducted relative to the moisture conditions assumed for geotechnical design. This paper presents a method for predicting changes in tip resistance as result of changes in matric suction. The method extends the bearing capacity theory to predict changes in cone tip resistance due to changes in matric suction. CPT data collected at test sites, during wet and dry seasons and representing different soil types, are presented to demonstrate the viability of the proposed method.
\end{abstract}

\section{Introduction}

Due to its rapidity and minimal dependence on the operator, the cone penetration test (CPT) is a valuable tool for characterizing soil stratigraphy and estimating soil properties for geotechnical analysis. A standard friction cone sounding [1] provides near continuous measurements of tip resistance $\left(q_{c}\right)$ and sleeve friction $\left(f_{s}\right)$ with depth that can be used to estimate soil type and mechanical properties such as shear strength, compressibility, and other soil properties [2-7]. Most of the methods for analysing CPT results for sands are based on completely saturated or dry conditions with no provision for considering degrees of saturation $(S)$ other than zero or unity. Similarly, methods of CPT interpretation for clays generally only consider saturated undrained conditions. However, in most instances the CPT sounding passes through a near surface zone of soil that it is an unsaturated state. Often this zone is critical to the support of overlying structures, particularly in the case of shallow foundations and mats. Depending on the time of subsurface exploration, the unsaturated zone may be particularly dry or wet depending on the season when the CPT soundings are conducted. Soil properties estimated from CPT soundings using traditional analysis techniques will likely overestimate the strength and stiffness of the soil if conducted during a dry season. Thus, there is a need to developed methods for interpreting CPT results that consider the degree of saturation and matric suction of the soil at the time the sounding is conducted. This paper presents a method based on bearing capacity theory that can be used to estimate the influence of degree of saturation and matric suction $\left(u_{a}-u_{w}\right)$ on $q_{c}$.

\section{Background}

\subsection{Overview}

The method of analysis presented in this paper is based on the soil water characteristic curve (SWCC) as presented by Zapata et al. [8], bearing capacity theory for quantifying cone penetration in soil [9] and shear strength of unsaturated soil as presented by Vanapalli et al. [10]. The bearing capacity equations are used to predict $q_{c}$ for a soil assuming drained conditions prevail and that the soil strength is defined by the friction angle and cohesion intercept. The cohesion in the case of a saturated soil is the effective stress cohesion intercept $\left(c^{\prime}\right)$ and for an unsaturated soil includes a contribution due to $u_{a}-u_{w}$. The relationship between $u_{a}-u_{w}$ and $S$ is defined by the SWCC. Thus, knowing the SWCC one can predict the relationship between $q_{c}$ and $u_{a}-u_{w}$.

\subsection{SWCC}

Zapata et al. [8] presented a method for predicting the SWCC for soil based on the plasticity index (PI) and

\footnotetext{
* Corresponding author: gamiller@,ou.edu
} 
percent passing the $\# 200$ sieve (w). In this paper, the percent passing the \#200 sieve or percent of fines is defined by the letter F instead of w. For non-plastic soils the SWCC is predicted based on diameter corresponding to $60 \%$ passing from the grain size distribution curve (D60). The Zapata et al. [8] method predicts the fitting parameters for the SWCC equation of Fredlund and Xing [11] as given by Eq. 1.

$$
\begin{gathered}
\theta_{w}=C(h)\left[\frac{\theta_{s}}{\left[\ln \left[\exp (1)+\left(\frac{h}{a}\right)^{b}\right]\right]^{c}}\right] \\
C(h)=\left[1-\frac{\ln \left(1+\frac{h}{h_{r}}\right)}{\ln \left(1+\frac{10^{6}}{h_{r}}\right)}\right]
\end{gathered}
$$

where: $\theta_{s}$ is saturated volumetric water content, $h$ is matric suction $\left(u_{a}-u_{w}\right) ; a, b, c$ and $h_{r}$ are fitting parameters related to the air entry pressure, rate of drainage, residual water content and corresponding suction, respectively.

For soils with PI greater than zero, equations can be used to estimate the fitting parameters if the PI and percent of fines, $\mathrm{F}$ (in decimal form) is known, as follows [8].

$$
\begin{gathered}
a=0.00364(F \times P I)^{3.35}+4(F \times P I)+11 \\
\frac{b}{c}=-2.313(F \times P I)^{0.14}+5 \\
c=0.0514(F \times P I)^{0.465}+0.5 \\
\frac{h_{r}}{a}=32.44 e^{0.0186(F \times P I)}
\end{gathered}
$$

For cohesionless soils with PI equal to zero, the SWCC parameters can be estimated based on D60, as follows.

$$
\begin{gathered}
a=0.8627(D 60)^{-0.751} \\
b=7.5 \\
c=0.1772 \ln (D 60)+0.7734 \\
\frac{h_{r}}{a}=\frac{1}{D 60+9.7 e^{-4}}
\end{gathered}
$$

If $\theta_{s}$ in Eq. 1 is unknown, it can be estimated for plastic and non-plastic soils using Eqs. 10 and 11, respectively.

$$
\begin{gathered}
\theta_{s}=0.0143(F \times P I)^{0.75}+0.36 \\
\theta_{s}=0.36
\end{gathered}
$$

\section{$2.3 q_{c}$ from Bearing Capacity Theory}

Durgunoglu and Mitchell [9] developed equations for predicting cone tip resistance for soils containing both stress dependent (friction angle, $\phi$ ) and stress independent (cohesion intercept, $c$ ) components of strength. Tip resistance based on bearing capacity theory is given by Eq. 12, as follows.

$$
q_{c}=c N_{c} \xi_{c}+\gamma_{s} B N_{\gamma q} \xi_{\gamma q}
$$

where: $c$ is the cohesion intercept of the Mohr-Coulomb failure envelope, $\gamma_{s}$ is the soil unit weight, $B$ is the cone base width, $N_{c}$ and $N_{\gamma_{q}}$ are bearing capacity factors, and $\xi_{c}$ and $\xi_{\gamma q}$ are shape factors. 14.

Bearing capacity factors [9] are given in Eqs. 13 and

$$
\begin{gathered}
N_{C}=A-B+C \\
A=\frac{(1+\sin \phi) \sin (2 \gamma-\phi)}{\sin \phi \cos \phi} e^{2 \theta_{o} \tan \phi} \\
B=\frac{1}{\tan \phi} \\
C=\frac{\cos (2 \gamma-\phi) \tan \psi}{\cos \phi} e^{2 \theta_{o} \tan \phi} \\
N_{\gamma q}=D(E+F-G+H)-I \\
D=\frac{\cos (\psi-\delta)}{\cos \delta} \frac{(1+\sin \phi)}{\cos \phi \cos (\gamma-\phi)} \\
E=\frac{\cos ^{2}(\gamma-\phi)}{4 \cos ^{2} \psi \cos ^{2} \phi} I_{\theta} \\
F=\frac{3 \cos (\gamma-\phi) \cos { }^{2} \beta}{4 \cos \psi \cos \phi} e^{2 \theta_{o} \tan \phi}\left(m-\frac{2}{3} m^{\prime}\right) \\
G=K \frac{\cos \psi \cos \phi}{\cos (\gamma-\phi)}\left(m-m^{\prime}\right)^{2}\left(m+2 m^{\prime}\right) \\
H=K \frac{\cos ^{\prime}(\cos \phi}{\cos (\gamma-\phi)} m^{3} \\
I=\frac{\tan \psi}{4}
\end{gathered}
$$

where: $N_{c}$ is the bearing capacity factor for the cohesion term, $N_{\gamma q}$ is the bearing capacity factor for frictionsurcharge, $\phi$ is soil friction angle, $\gamma$ is the top most angle of the plane shear zone, $\psi=90^{\circ}-\alpha, \alpha=1 / 2$ the cone apex angle, $\theta_{o}=180^{\circ}-(\psi+\gamma)+\beta, \delta$ is the cone base to soil friction angle, $K$ is lateral earth pressure coefficient, $m$ is relative depth $(D / B), D$ is cone tip depth, and $B$ is cone diameter.

$$
\begin{gathered}
m^{\prime}=\frac{1}{2} \frac{\sin \beta \cos (\gamma-\phi)}{\cos \psi \cos \phi} e^{\theta_{o} \tan \phi} \\
I_{\theta}=J(K+L) \\
J=\frac{1}{1+9 \tan ^{2} \phi} \\
K=3 \tan \phi\left[e^{3 \theta_{o} \tan \phi} \cos \beta-\cos \left(\theta_{o}-\beta\right)\right] \\
L=e^{3 \theta_{o} \tan \phi} \sin \beta+\sin \left(\theta_{o}-\beta\right)
\end{gathered}
$$

The angles $\gamma, \psi, \theta_{o}$ and $\beta$, and parameters $m$ ' and $I_{\theta}$ relate to geometry of the assumed rupture surface around the cone tip, as shown in Durgunoglu and Mitchell [9]. 
The angle $\beta$ depends on the soil friction angle ( $\phi$ ), relative depth of penetration $(m)$, roughness ratio $(\delta / \phi)$, and cone apex angle $(2 \alpha)$. For large relative depths the angle $\beta$ will be equal to the soil friction angle, $\phi$. For a standard cone $\left(\alpha=30^{\circ}\right)$ penetration depths greater than ten to thirty times the cone diameter $(D / B>10$ to 30$)$ can be considered large depending on the roughness ratio $(\delta / \phi)$. For a standard cone with a diameter of $0.0357 \mathrm{~m}$, a $D / B$ of thirty would correspond to a depth of penetration of $1.1 \mathrm{~m}$. Angle $\gamma$ depends on $\phi$ and $\delta / \phi$; for a perfectly rough condition $(\delta / \phi=1) \gamma$ is equal to zero and for perfectly smooth condition $(\delta / \phi=0)$ it varies nearly linearly from $50^{\circ}$ to $70^{\circ}$ for $\phi$ between $10^{\circ}$ and $50^{\circ}$. For $\delta / \phi=0.5$, angle $\gamma$ varies nearly linearly from $32.4^{\circ}$ to $40.8^{\circ}$ for $\phi$ between $10^{\circ}$ and $50^{\circ}$.

Shape factors $\xi_{c}$ and $\xi_{\gamma q}$ depend on the penetrometer aspect ratio and soil friction angle, and $\xi_{\gamma q}$ also depends on the relative depth of penetration. Durgunoglu and Mitchell [9] used the semi-empirical shape factors suggested by Hansen [12], as these were found to provide the best match to their experimentally determined values. These values were adopted here; for deep penetration, $\xi_{c}$ and $\xi_{\gamma q}$ are the same and calculated using Eq. 17.

$$
\xi_{c}, \xi_{\gamma q}=1.0+\left(0.2+\tan ^{6} \phi\right)(B / L)
$$

where: $B / L$ was taken as 1 .

\subsection{Shear Strength of Unsaturated Soil}

The shear strength of unsaturated soil was modelled using Eq. 18 proposed by Vanapalli et al. [10].

$$
\tau=c^{\prime}+\left(\sigma_{n}-u_{a}\right) \tan \phi^{\prime}+\left(u_{a}-u_{w}\right) \tan \phi^{\prime} \frac{\left(\theta-\theta_{r}\right)}{\left(\theta_{s}-\theta_{r}\right)}
$$

where: $\tau$ is the shear stress on the failure plane at failure, $c^{\prime}$ is the effective stress cohesion intercept, $\sigma_{n}-u_{a}$ is the net normal stress on the failure plane at failure, $\sigma_{n}$ is total normal stress on failure plane, $u_{a}$ is pore air pressure, $\phi^{\prime}$ is effective stress friction angle, $u_{a}-u_{w}$ is matric suction, $u_{w}$ is pore water pressure, $\theta$ is volumetric water content, $\theta_{r}$ is residual volumetric water content, and $\theta_{s}$ is saturated volumetric water content.

For drained shearing the effective strength parameters $c^{\prime}$ and $\phi$ ' are typically assumed to be constant and equal to values obtained for saturated soils. For unsaturated soil the component of strength associated with matric suction can be represented by Eq. 19 .

$$
c=c^{\prime}+\left(u_{a}-u_{w}\right) \tan \phi^{\prime} \frac{\left(\theta-\theta_{r}\right)}{\left(\theta_{s}-\theta_{r}\right)}
$$

Given the SWCC, the drained shear strength for unsaturated soil can be defined for the entire range of matric suction. Values of $c$ from Eq. 19 can then be substituted in Eq. 12 to predict $q_{c}$ corresponding to a range of $u_{a}-u_{w}$ defined by Eq. 1 .

\section{Predictions of $q_{c}$ based on SWCC}

SWCC curves for a range of typical soils predicted using Eqs. 1 through 11 are shown in Figure 1. Curves for three plastic soils ( $\mathrm{PI}=50,20,5$ and $\mathrm{F}=100 \%)$ and three nonplastic soils $(\mathrm{PI}=0, \mathrm{D} 60=0.06,0.4$ and $2 \mathrm{~mm})$ are shown.
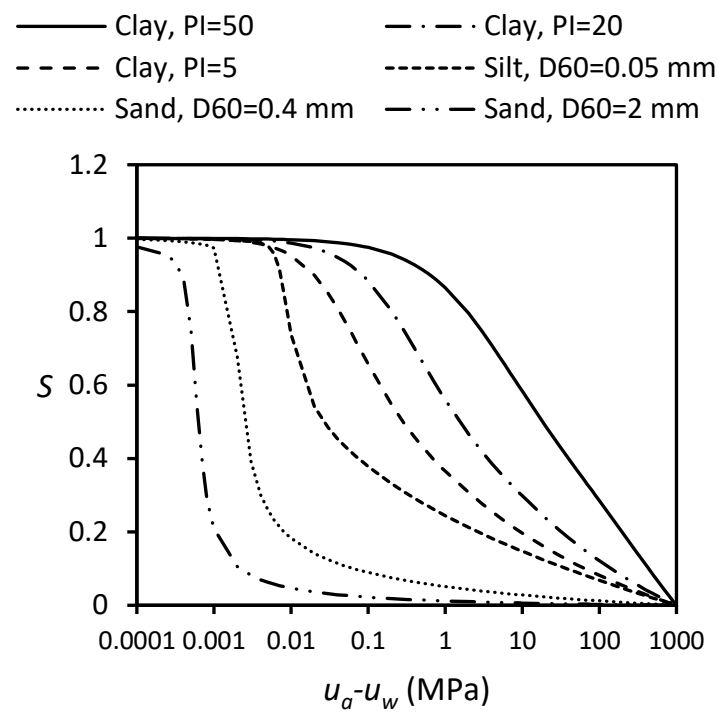

Fig. 1. Typical SWCCs for plastic and non-plastic soils.

Using the SWCCs in Fig. 1, Eq. 19 and Eq. 12, predictions of $q_{c}$ versus $u_{a}-u_{w}$ were made and are shown in Fig. 2. To generate curves in Fig. 2, $\phi^{\prime}$ of $30^{\circ}$ was used for all of the soils, $c$ ' of $0.01 \mathrm{MPa}$ was used for clay soils and zero was used for non-plastic soils. In addition, a roughness ratio of 0.5 was used and lateral earth pressure coefficient $K$ was assumed equal to $1-\sin \phi$ '.

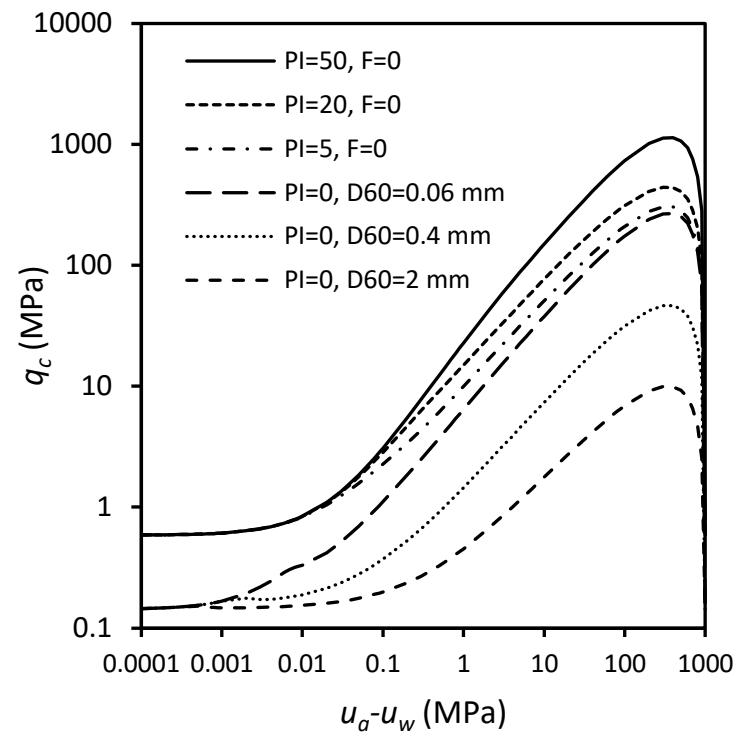

Fig. 2. Predicted cone tip resistance using bearing capacity theory and SWCCs from Fig. 1.

Predicted curves in Fig. 2 indicate that $q_{c}$ is very sensitive to $u_{a}-u_{w}$. It increases rapidly between $u_{a}-u_{w}$ of 0.1 and $100 \mathrm{MPa}$, after which it peaks and begins to decrease rapidly to zero as the degree of saturation approaches zero.

While there are a number of assumptions involved in developing predicted $q_{c}$ curves shown in Fig. 2, they 
provide some insight in how $q_{c}$ may vary with moisture conditions and matric suction. If actual SWCC data are available, $q_{c}-\left(u_{a}-u_{w}\right)$ curves for soils from actual CPT sites can be generated corresponding to different strength parameters $\left(\phi^{\prime}, c^{\prime}\right)$. Alternatively, the empirical equations (Eqs. 2-11) along with Eq. 1 can be used to generate SWCCs based on soil index properties and used to predict $q_{c}-\left(u_{a}-u_{w}\right)$ curves. By superimposing CPT $q_{c}$ values corresponding to different $u_{a}-u_{w}$ from field measurements on a family of predicted $q_{c}-\left(u_{a}-u_{w}\right)$ curves, it is possible to predict how $q_{c}$ in the field may change with changing moisture and suction conditions. This requires that companion moisture content and estimated matric suction profiles be determined at the same time CPT soundings are conducted.

\section{Application of the Method to $q_{c}$ Values Obtained at Two Test Sites}

To demonstrate how predicted $q_{c}-\left(u_{a}-u_{w}\right)$ curves can be used to estimate how $q_{c}$ may change with changing moisture conditions, CPT data from two test sites were used. The North Base test site consists of moderate to moderately high plastic soils. Soil layers at North Base were placed in two categories based on their percent of fines and plasticity index. North Base 1 (NB1) soils had an average PI of 29 and average F of $91 \%$. North Base 2 (NB2) soils had an average PI and F of 19 and $89 \%$, respectively. The Goldsby test site consisted of moderate PI soils with layers similarly grouped into two categories. Goldsby 1 (G1) soils had an average PI and F of 11 and $92 \%$ while Goldsby 2 (G2) soils had average values of 9 and $80 \%$, respectively. At each of these test sites, CPT soundings were conducted seven times over a period of 2 years, in the upper $3 \mathrm{~m}$ of the profile. On each sounding date, moisture content samples were obtained at every $0.305 \mathrm{~m}$ of depth and matric suction was estimated based on SWCCs determined for each test site. On each date, three CPT soundings were obtained and average $q_{c}$ values for each moisture content depth were calculated. More detailed information about the CPT and laboratory testing for the test sites can be found in Miller et al. [13].

To demonstrate the method, using Eqs. 1 through 11 the SWCC curves in Fig. 3 were first developed. Then using Eq. 19 and 12, a family of predicted $q_{c}-\left(u_{a}-u_{w}\right)$ curves was developed for each test site soil category for a range of $\phi^{\prime}\left(10-40^{\circ}\right)$ and $c^{\prime}(0.0-0.04 \mathrm{MPa})$ values. In Figs. 4 to 7 , the predicted family of curves for each test site soil category are shown along with the field CPT $q_{c}$ values. Note that unlike Fig. 2, the graphs in Figs. 4 to 7 are semi$\log$ and $\mathrm{x}$ and $\mathrm{y}$ axis ranges have been adjusted to better show the CPT field data. While the field data are somewhat scattered they generally exhibit trends consistent with the trends of the family of curves.

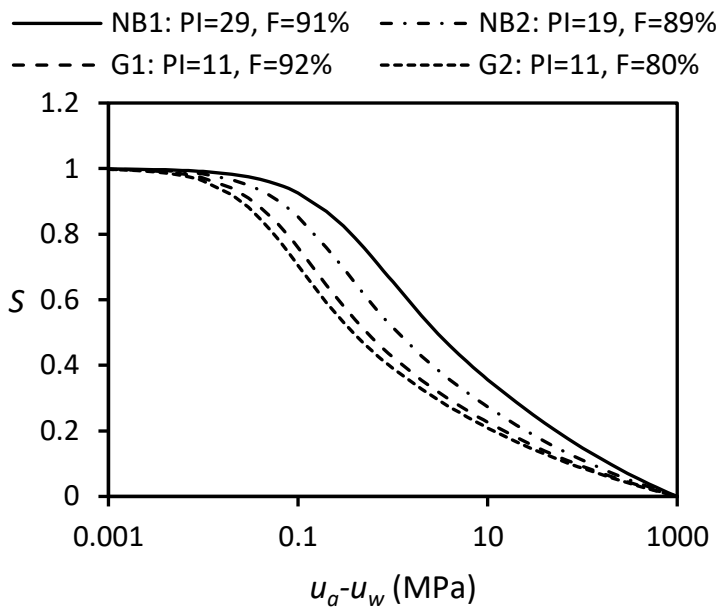

Fig. 3. SWCC curves predicted for North Base and Goldsby CPT sites using Eqs. 1 through 11.

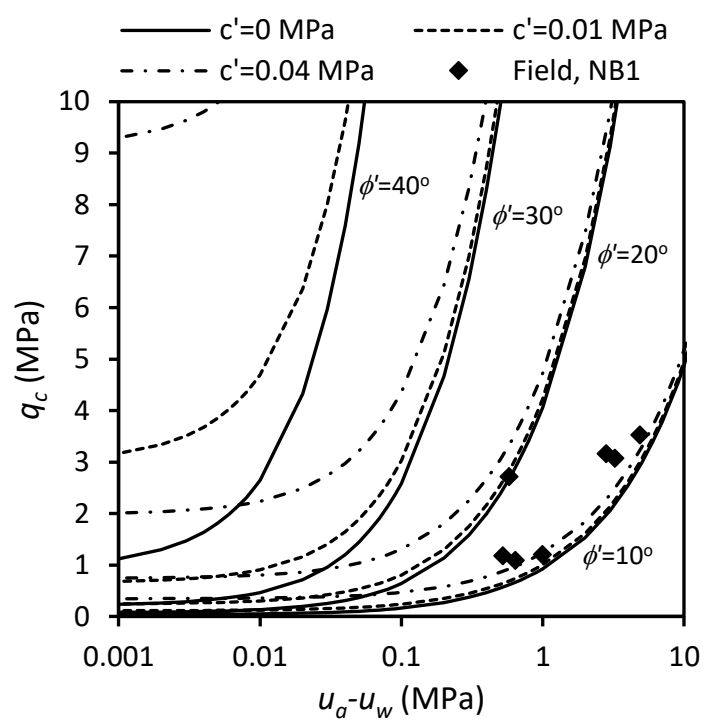

Fig. 4. Predicted $q_{c}-\left(u_{a}-u_{w}\right)$ curves and field $q_{c}$ data for NB1.

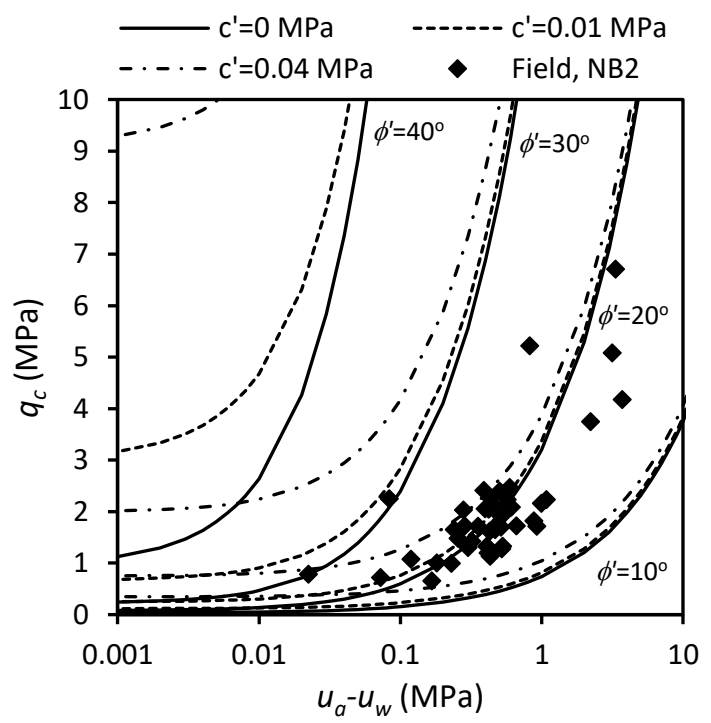

Fig. 5. Predicted $q_{c}-\left(u_{a}-u_{w}\right)$ curves and field $q_{c}$ data for NB2. 


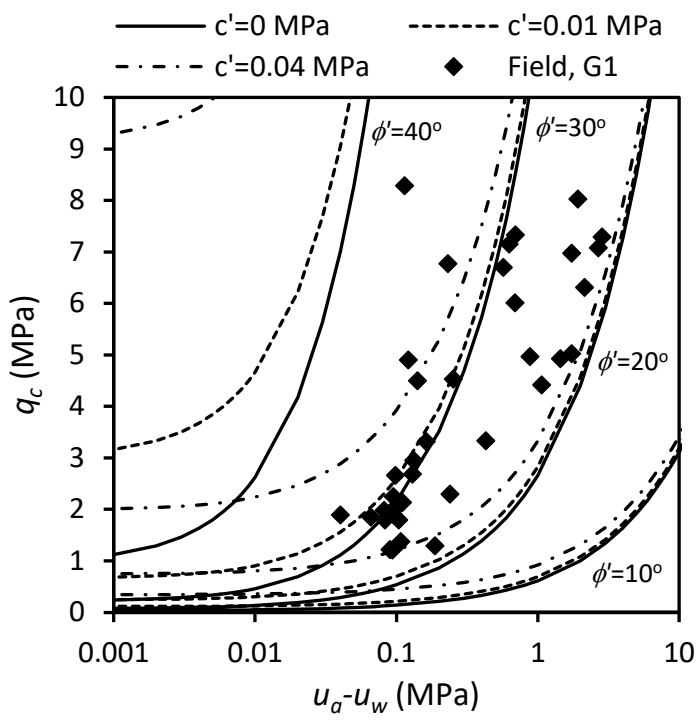

Fig. 6. Predicted $q_{c}-\left(u_{a}-u_{w}\right)$ curves and field $q_{c}$ data for G1.

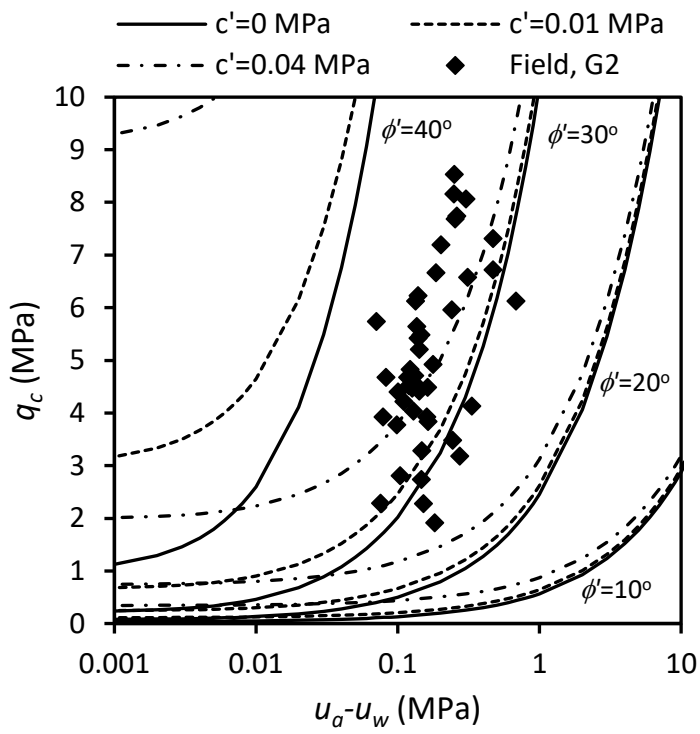

Fig. 7. Predicted $q_{c}-\left(u_{a}-u_{w}\right)$ curves and field $q_{c}$ data for $\mathrm{G} 2$.

Using the predicted curves as a guide, the trend in field CPT values in Figs. 4 to 7 can be extrapolated to estimate $q_{c}$ values beyond the range of suction values encompassed by the CPT data. Another approach to applying this method is to manipulate the $\phi^{\prime}$ and $c^{\prime}$ values to provide a more exact match to the trend of field $q_{c}$ values. This is demonstrated in Figs. 8 to 11. Also shown in Figs. 8 to 11 is the influence of the roughness ratio on the predictions. Similar predictions in the trend lines can be obtained using $\delta / \phi^{\prime}$ of 0.0 and 0.5 by adjusting $\phi^{\prime}$ accordingly.

\section{Discussion}

Use of the bearing capacity theory to predict $q_{c}$ values involves many assumptions and ignores certain limitations in the theory. As discussed by Yu and Mitchell [14], use of bearing capacity analysis does not consider the dependence of tip resistance on soil stiffness and compressibility, or the influence of the penetration process on the stresses, which generally includes an increase in horizontal stresses around the cone. It was also assumed that the lateral stress ratio was equal to $1-\sin \phi$, which is generally applicable to normally consolidated soils. The analysis was based on the assumption of deep penetration, which corresponds in theory to penetration depths greater than 30 cone diameters. For soils with depths of penetration less than 30 cone diameters some adjustments in bearing capacity factors and shape parameters should be included. An assumption of drained shearing with constant suction is implicit in this analysis; however, for soils close to saturation this assumption is probably not valid, particularly for fine grained soils. In spite of these limitations, the predicted trends in $q c-\left(u_{a^{-}}\right.$ $u_{w}$ ) curves provide much needed insight into how cone tip resistance may vary in response to changes in matric suction. Results of this study show that bearing capacity theory has great potential for advancing our understanding and analysis of CPT tip resistance. However, there is a need to further explore and overcome the limitations mentioned above.

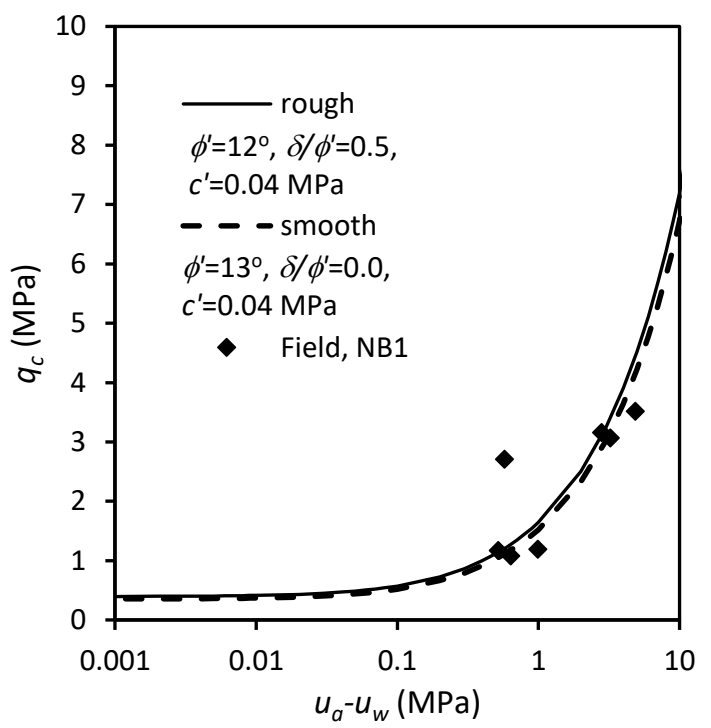

Fig. 8. Best fit $q_{c}-\left(u_{a}-u_{w}\right)$ curves for field $q_{c}$ data from NB1.

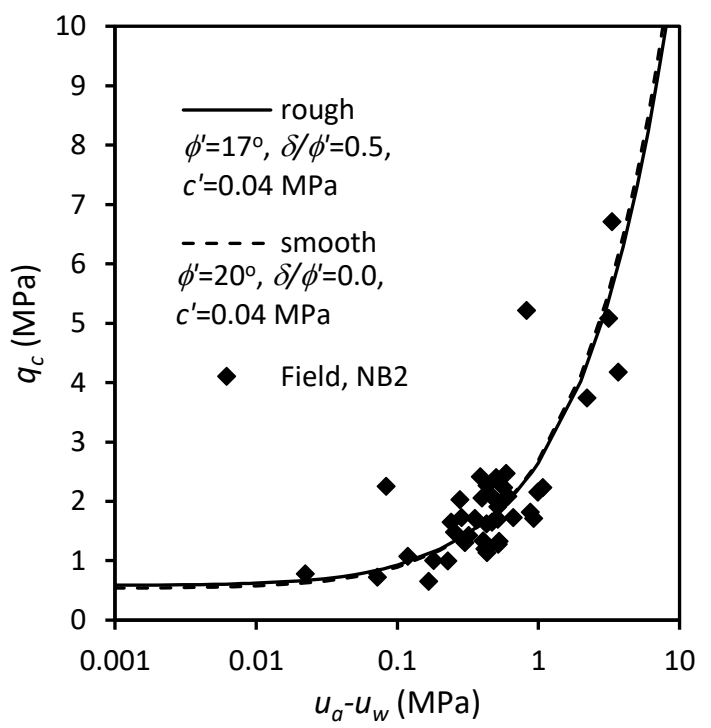

Fig. 9. Best fit $q_{c}-\left(u_{a}-u_{w}\right)$ curves for field $q_{c}$ data from NB2. 


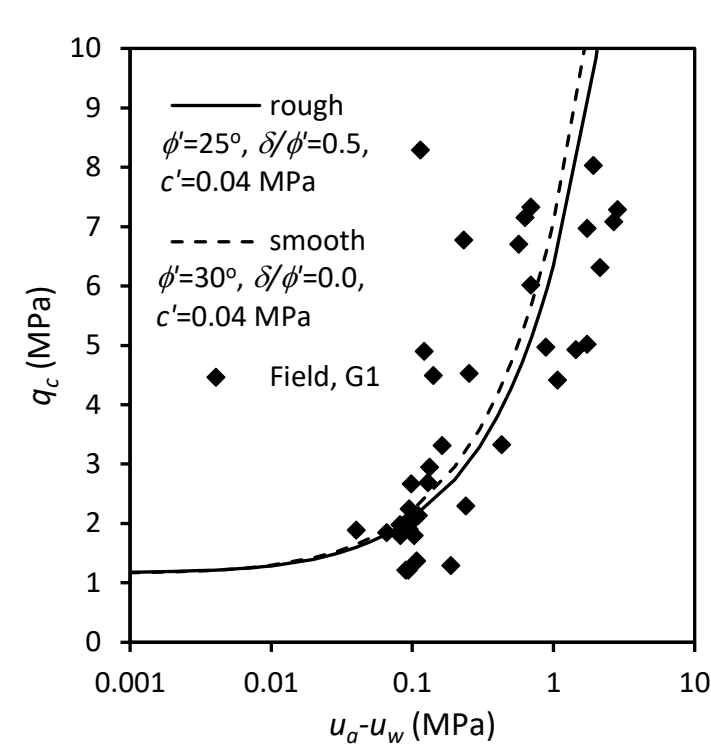

Fig. 10. Best fit $q_{c}-\left(u_{a}-u_{w}\right)$ curves for field $q_{c}$ data from G1.

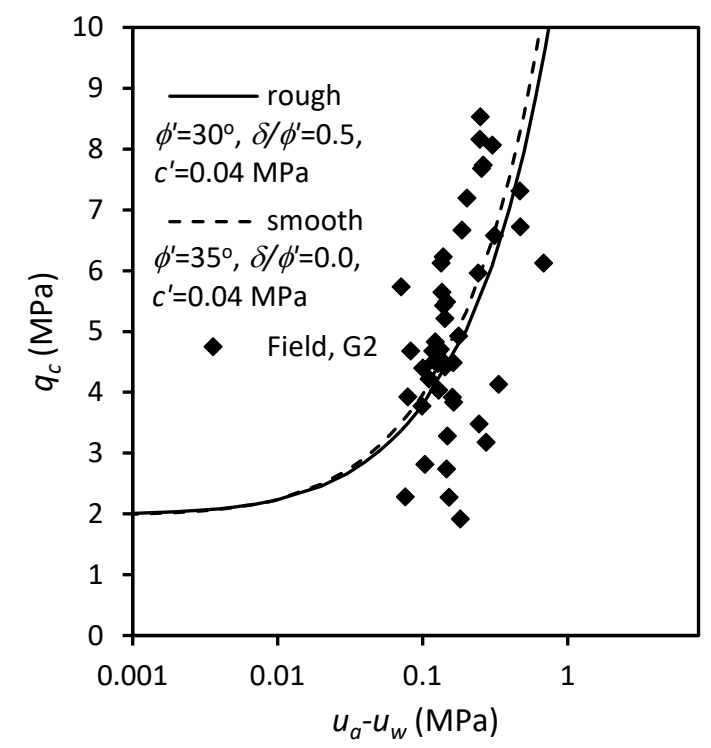

Fig. 11. Best fit $q_{c}-\left(u_{a}-u_{w}\right)$ curves for field $q_{c}$ data from $\mathrm{G} 2$.

\section{Conclusions}

A method for predicting the influence of matric suction on cone tip resistance based on bearing capacity theory [9] was presented in this paper. The procedure outlined utilizes predicted soil water characteristics curves based on the Zapata et al. [8] empirical method and the Vanapalli et al. [10] shear strength equation. A comparison of CPT tip resistance data from two test sites with predicted trends of tip resistance versus matric suction, indicates that the method holds promise for analysis of tip resistance in unsaturated soil. As noted in the paper, there are assumptions and limitations involved in this method that require additional research.

The authors are grateful to the Oklahoma Department of Transportation (ODOT) and Oklahoma Transportation Center for their financial support of field research via Grant No. OTCREOS11.1-45. Additional thanks to ODOT for conducting CPTs and test borings during field research.

\section{References}

1. ASTM. D5778-12 Standard test method for electronic friction cone and piezocone penetration testing of soils. Annual Book of ASTM Standards, 4, 1587-1605 (2012)

2. P.K. Robertson, R.G. Campanella. Interpretation of cone penetration tests. Part I: Sand. Canadian Geotechnical Journal, 20(4), 718-733 (1983)

3. P.K. Robertson, R.G. Campanella. Interpretation of cone penetration tests. Part II: Clay. Canadian Geotechnical Journal, 20(4), 734-745 (1983)

4. P.W. Mayne, J.B. Kemper. Profiling OCR in stiff clays by CPT and SPT. Geotechnical Testing Journal, 11(2), 139-147 (1988).

5. P.K. Robertson. Interpretation of cone penetration tests - a unified approach. Canadian Geotechnical Journal, 46(11), 1337-1355 (2009)

6. S.R. Saye, A.J. Lutenegger, J. Santos, B.P. Kumm. Assessing overconsolidation ratios in soil with piezocone: referencing soil index properties. Journal of Geotechnical and Geoenvironmental engineering, 139(7), 1075-1085 (2013)

7. P.K. Robertson. Cone penetration test (CPT)-based soil behaviour type (SBT) classification system - an update. Canadian Geotechnical Journal, 53(12), 1910-1927 (2016)

8. C.E. Zapata, W.N. Houston, S.L. Houston, K.D. Walsh. Soil-water characteristic curve variability. ASCE, GSP 99, 84-124 (2000)

9. H.T. Durgunoglu, J.K. Mitchell. Static penetration resistance of soils. For NASA Grant NGR 05-003406: Lunar Soil Properties and Soil Mechanics, Space Sciences Laboratory Series 14, Issue 24, UC Berkeley, 223 p. (1973)

10. S.K. Vanapalli, D.G. Fredlund, D.E. Pufahl, A.W. Clifton. Model for the prediction of shear strength with respect to soil suction. Canadian Geotechnical Journal, 33(3), 379-392 (1996)

11. D.G. Fredlund, A. Xing. Equations for the soil-water characteristic curve. Canadian Geotechnical Journal, 31(4), 521-532 (1994)

12. B. Hansen. A general formula for bearing capacity. Danish Geotechnical Institute, Bulletin, 11, 38-46 (1961)

13. G.A. Miller, R.W. Collins, N.K. Tan, K.K. Muraleetharan. Cone penetration testing in unsaturated soils. Transportation Geotechnics, 17, 85-99 (2018)

14. H.S. Yu, J.K. Mitchell. Analysis of cone resistance: review of methods. Journal of Geotechnical and Geoenvironmental Engineering, 124(2), 140-149 (1998) 